\title{
Genotyping FOXG1 Mutations in Patients with Clinical Evidence of the FOXG1 Syndrome
}

\author{
D.W. Pratt ${ }^{a}$ J.V. Warner ${ }^{a} \quad$ M.G. Williams ${ }^{a}$ b \\ Departments of a Mater Pathology and ${ }^{b}$ Molecular Genetics, Mater Adult Hospital, South Brisbane, Qld., Australia
}

\section{Key Words}

FOXG1 $\cdot \mathrm{MECP} 2 \cdot \operatorname{Rett} \cdot$ Variant Rett

\begin{abstract}
Rett syndrome is a well-defined neurodevelopmental disorder comprising characteristic clinical features of gait abnormalities, loss of purposeful hand movements, stereotypies, and autistic features. Mutations in the FOXG1 gene have been associated with a congenital variant of Rett syndrome. This is a report on the outcome of routine genetic testing to identify FOXG1 mutations in a patient population presenting with features of the FOXG1 syndrome, an entity thought to be distinct, but similar, to the congenital variant of Rett syndrome. We performed $P C R$ and sequencing analysis of FOXG1 in MECP2-negative patients $(n=12)$ with phenotypic features of FOXG1 syndrome. FOXG1 MLPA analysis was also carried out. No mutations in FOXG1 were identified using this approach. We were unable to identify patients with features of the FOXG1 syndrome as having aberrant FOXG1 gene loci. Clinical notes are inherently subjective and may lack sufficient detail to reliably identify those with a syndromal spectrum. The results call into question the objectivity of outlining a complex syndrome according to clinical manifestations and highlight the need for a greater involvement of molecular diagnostic techniques in the diagnosis of Rett-like disorders.

Copyright $\odot 2012$ S. Karger AG, Basel
\end{abstract}

\section{KARGER}

Fax +4161306 1234

E-Mail karger@karger.ch

www.karger.com (c) 2012 S. Karger AG, Basel

$1661-8769 / 12 / 0036-0284 \$ 38.00 / 0$

Accessible online at:

www.karger.com/msy
Classic Rett syndrome is a severe X-linked neurodevelopmental disorder involving characteristic regression of previously acquired developmental milestones, including spoken language and gait, and involves the introduction of stereotypic movements and automatisms [Neul et al., 2010]. First described in the 1960s, the disorder has since undergone diagnostic revision incorporating novel phenotype-genotype correlations [Hagbergg and Skjeldal, 1994; Neul et al., 2010]. Classic Rett syndrome is a distinct clinical entity that involves mutations $(80 \%)$ in the gene encoding methyl-CpG-binding protein 2 (MECP2), leading to aberrations in epigenetic control with subsequent neurological problems [ $\mathrm{Na}$ and Monteggia, 2011]. Some patients, however, lack some of the clinical characteristics of typical or classic Rett syndrome and thus have been said to have 'variants' of the disorder [Neul et al., 2010]. These variants have been shown to be associated with mutations in other genes, including patients with earlyonset seizures having CDKL5 mutations [Weaving et al., 2005] and those with Rett features from birth having FOXG1 mutations [Ariani et al., 2008]. While there is some overlap, current research and case studies do suggest distinct differences in the presentation of patients with mutations in the FOXG1 locus and those with MECP2 and CDKL5 mutations [Neul et al., 2010]. The clinical deterioration seen in these patients is consistent with current laboratory research regarding the functions 
of these loci in neural development [Mari et al., 2005; Roth et al., 2010]. The following discussion supports a move towards a genetic and biochemical definition of syndromes that manifest from these genetic mutations.

The diagnosis of Rett syndrome, at present, rests on a clinical evaluation and has recently been given new criteria [Neul et al., 2010]. According to the revised criteria, there must be a period of regression following birth with loss of hand skills, spoken language, the presence of gait abnormalities, and hand stereotypy; those who do not exhibit a clear period of regression have been designated 'possible Rett syndrome' [Neul et al., 2010]. Naidu and Johnston [2011] point out that, while the syndrome has classically been a clinical diagnosis, there may be too much of a reliance on these features with the new revised criteria. The authors also call into question the designation of 'possible' Rett syndrome and emphasize that some of the cardinal features of Rett syndrome (i.e. regression) may not necessarily be present in those who have mutations in the gene associated with the classic form of the syndrome (MECP2) [Naidu and Johnston, 2011]. Accordingly, it has been emphasized by some that other genetic abnormalities, such as those seen in the FOXG1 gene, be considered in patients with Rett-like features who test negative for MECP2 mutations [Naidu and Johnston, 2011; Van der Aa et al., 2011]. The clinical overlap of Rett syndrome with other neurodevelopmental disorders has also created problems in identifying these patients early in the disease course [Ellaway et al., 1998]. The phenotype seen in other disorders, such as Angelman syndrome, can easily be confused with Rett syndrome [Kortüm et al., 2011], thus, making clinical evaluation alone seemingly insufficient. This overlap is also seen in patients with FOXG1 and CDKL5 mutations and in early onset infantile Rett syndrome [Rajaei et al., 2010]. This ambiguity has led to a push for identifying molecular and genetic aberrations to complement clinical diagnostic standards [BahiBuisson et al., 2010; Kortüm et al., 2011; Naidu and Johnston, 2011]. Following the recent revision of the diagnostic criteria for Rett syndrome, Kortüm et al. [2011] pointed out potential diagnostic gaps in redefining atypical Rett syndrome. This has led to a proposed new syndrome, 'FOXG1 syndrome', based on mutations in FOXG1 and with clinical features which distinguish it from the previously defined congenital variant of Rett syndrome. Some of the key distinctions include characteristic brain imaging findings (e.g. hypogenesis of the corpus callosum), dyskinesias and the aforementioned lack of regression [Kortüm et al., 2011]; the latter being a key criterion in Rett syndrome [Neul et al., 2010].
Consistent identification of these patients using genetic techniques remains an active area of research. Indeed, not all patients with classic Rett syndrome harbour mutations in $M E C P 2$, and the presence of MECP2 mutations does not necessarily correlate with the aforementioned phenotype [Christodoulou and Weaving, 2003]; this 'heterogeneity' has been attributed to the effect of random $\mathrm{X}$-inactivation [Mari et al., 2005]. Furthermore, there have also been a number of cases reported in male patients, who traditionally were understood to succumb in utero. Le Guen et al. [2011] reported the first case of a point mutation in the FOXG1 gene in a male patient with clinical features of atypical Rett syndrome. Van der Aa et al. [2011] reported the presence of both male and female de novo mutations in FOXG1, further supporting the notion that this is not a female-exclusive disease and that genetic testing should be broadened to include candidate autosomal genes. Indeed, while the inheritance pattern of classic Rett syndrome is X-linked, atypical cases have been shown to involve both sex-linked (CDKL5) [Weaving et al., 2005] and autosomal chromosomes (FOXG1) [Ariani et al., 2008]. Recommendations are now being made to incorporate males in screening procedures [Van der Aa et al., 2011], a previous oversight possibly resulting from the generalization of Rett syndrome being a femaleonly disease [Takashi et al., 2011].

To contribute to the discussion on the applicability of clinical and genetic classification of patients with Rettlike syndromes, we report the results of genetic testing for mutations in the FOXG1 gene in patients with features of the newly proposed FOXG1 syndrome [Kortüm et al., 2011]. In routine genetic testing for Rett syndrome, our laboratory stratifies patients who are negative for $M E C P 2$ mutations for further testing. From a total of 29 MECP2mutation negative patients, 12 patients ( 9 female, 3 male) that exhibited features consistent with the proposed FOXG1 syndrome [Kortüm et al., 2011] were genotyped; this information was based on clinical details submitted by the requesting clinician on the test request form. Specifically, patients presenting with combinations of the following characteristics were subjected to further genetic analysis: postnatal growth deficiency, microcephaly, mental retardation, deficient language development, deficient social interactions, stereotypies and dyskinesias, epilepsy, poor sleep patterns, irritability, excessive crying, recurrent aspiration, and frequent gastro-esophageal reflux [Kortüm et al., 2011]. Note that not all characteristics of FOXG1 syndrome were present in this group of patients. Mean age at the time of testing was 6 years. Exon 1 of the forkhead box G1 (FOXG1) gene was analysed for 
point mutations using polymerase chain amplification and Sanger sequencing. Sequences were compared to the NCBI reference NM_005249 [Kortüm et al., 2011]. In addition to point mutations, copy number variations have been reported in patients with the FOXG1 syndrome [Kortüm et al., 2011]. Therefore, FOXG1 Multiplex Ligation-dependent Probe Amplification (MRC-Holland) was performed on DNA samples of satisfactory quality for this testing (10 out of 12 patients). Karyotyping analysis was also performed prior to genotyping. Brain imaging (MRI) results were ascertained and compared to findings in patients with FOXG1 syndrome.

No mutations in the FOXG1 gene or copy number variations were found using this stratification. The reason for this may have been in the selection of patients for testing, due to the available clinical details. However, the provision of inaccurate or incomplete clinical details is an ageold problem for laboratory testing, and given the paucity of data regarding this new syndrome and its similarity to Rett variants, other features of FOXG1 syndrome may be present, but not identified or recorded. In an epidemiological study on Rett syndrome in Australia, Laurvick et al. [2006] identified factors that may account for this, such as incompleteness of diagnosis and follow-up, age of patients at presentation and a questionable standardization of subcategories of Rett syndrome (e.g. atypical vs. typical presentation). Given the significant phenotypegenotype variability in patients with features of Rett syndrome [Weaving et al., 2005], stratified genetic testing using available clinical information is not an unreasonable approach.
Analysis of MRI revealed abnormalities in only 3 of the 12 patients in our cohort. These changes included microcephaly, simplified gyral pattern, early myelination, subcortical leukodystrophy, and corpus collosum hypoplasia. While some of these features have been reported in patients with FOXG1 mutations, there is a lack of consistency in the literature regarding the presence or absence of MRI findings for patients within this spectrum of clinical findings [Philippe et al., 2009]; thus, imaging results should be taken in context with mutation analysis and clinical presentation. Furthermore, the presence of similar MRI abnormalities in CDKL5 [Bahi-Busson et al., 2008] and MECP2-positive patients [Mahmood et al., 2010], as well as other causes of developmental delay [Ünal et al., 2009], suggest imaging is a nonspecific test for these patients.

Unlike classic Rett syndrome, the precise symptomatology and clinical presentation of the FOXG1 syndrome have only recently been published and may be revised over time. Given that the genesis of this syndrome stems from its similarity to a Rett syndrome variant, diagnostic confirmation using molecular techniques seems warranted. In this new age of high-throughput, relatively low-cost genetic testing, we suggest that patients with features of Rett syndrome may be best investigated with a genotyping panel, in addition to routine chromosome analysis; for example, using massively parallel exome analysis, covering all known candidate genes, including MECP2, FOXG1 and CDKL5. Additionally, the use of imaging modalities such as CT or MRI can help detect characteristic cerebral anomalies seen in this group of patients [Kortüm et al., 2011], thus improving clinical sensitivity.

\section{References}

Ariani F, Hayek G, Rondinella D, Artuso R, Mencarelli MA, et al: FOXG1 is responsible for the congenital variant of Rett syndrome. Am J Hum Genet 83:89-93 (2008).

-Bahi-Buisson N, Nectoux J, Rosas-Vargas H, Milh M, Boddaert N, et al: Key clinical features to identify girls with CDKL5 mutations. Brain 131:2647-2661 (2008).

Bahi-Buisson N, Nectoux J, Girard B, Van Esch $\mathrm{H}$, De Ravel T, et al: Revisiting the phenotype associated with FOXG1 mutations: two novel cases of congenital Rett variant. Neurogenetics 11:241-249 (2010)

Christodoulou J, Weaving L: MECP2 and beyond: phenotype-genotype correlations in Rett syndrome. J Child Neurol 18:669-74 (2003).

\footnotetext{
Ellaway C, Buchholz T, Smith A, Leonard H, Christodoulou J: Rett syndrome: significant clinical overlap with Angelman syndrome but no with methylation status. J Child Neurol 13:448-451 (1998).

Hagbergg BA, Skjeldal O: Rett variants: a suggested model for inclusion criteria. Pediatr Neurol 11:5-11 (1994).

Kortüm F, Das S, Flindt M, Morris-Rosendahl DJ, Stefanova I, et al: The core FOXG1 syndrome phenotype consists of postnatal microcephaly, severe mental retardation, absent language, dyskinesia, and corpus callosum hypogenesis. J Med Genet 48:396-406 (2011). lou J, Ravine D, et al: Rett syndrome in Australia: a review of the epidemiology. J Pediatr 148:347-52 (2006).

Le Guen T, Bahi-Buisson N, Nectoux J, Boddaert N, Fichou Y, et al: A FOXG1 mutation in a boy with congenital variant of Rett syndrome. Neurogenetics 12:1-8 (2011).

Mahmood A, Bibat G, Zhan AL, Izbudak I, Farage $\mathrm{L}$, et al: White matter impairment in Rett syndrome: diffusion tensor imaging study with clinical correlations. Am J Neuroradiol 31:295-99 (2010).

Mari F, Kilstrup-Nielsen C, Cambi F, Speciale C, Mencarelli MA, Renieri A: Genetics and mechanisms of disease in Rett syndrome. Drug Discov Today 2:419-425 (2005).
} 
Na ES, Monteggia LM: The role of MeCP2 in CNS development and function. Horm Behav 59:364-368 (2011)

-Naidu S, Johnston MV: Clinical criteria for Rett syndrome. Nat Rev Neuro 7:312-314 (2011).

- Neul JL, Kaufmann WE, Glaze DG, Christodoulou J, Clarke AJ, et al: Rett syndrome: revised diagnostic criteria and nomenclature. Ann Neurol 68:944-950 (2010).

Philippe C, Amsallem D, Francannet C, Lambert L, Saunier A, et al: Phenotypic variability in Rett syndrome associated with FOXG1 mutations in females. J Med Genet 47:59-65 (2009).
Rajaei S, Erlandson A, Kyllerman M, Albage M, Lundstrom I, et al: Early infantile onset 'congenital' Rett syndrome variants: Swedish experience through four decades and mutation analysis. J Child Neurol 26:65-71 (2010).

Roth M, Bonez B, Lindsay J, Lea R, Panagiotaki $\mathrm{N}$, et al: FoxG1 and TLE2 act cooperatively to regulate ventral telencephalon formation. Development 137:1553-1562 (2010).

Takashi S, Matsumoto N, Okayama A, Suzuki N, Araki A, et al: FOXG1 mutations in Japanese patients with the congenital variant of Rett syndrome. Clin Genet 82:569-573 (2012).
Ünal Ö, Özcan Ö, Öner Ö, Akcakin M, Aysev A, Deda G: EEG and MRI findings and their relation with intellectual disability in pervasive developmental disorders. World J Pediatr 5:196-200 (2009).

Van der Aa N, Van den Bergh M, Ponomarenko N, Verstraete L, Ceulemans B, Storm K: Analysis of FOXG1 is highly recommended in male and female patients with Rett syndrome. Mol Syndromol 6:290-293 (2011).

Weaving LS, Ellaway CJ, Gecz J, Christodoulou $\mathrm{J}$ : Rett syndrome: clinical review and genetic update. J Med Genet 42:1-7 (2005). 